\title{
Flavonoid Analysis and Antioxidant Activities of the Bryonia alba L. Aerial Parts
}

\author{
Irina Ielciu ${ }^{1,2}$, Michel Frédérich ${ }^{2}(0)$, Daniela Hanganu ${ }^{3, *}$, Luc Angenot ${ }^{2}$, Neli-Kinga Olah ${ }^{4,5}$, \\ Allison Ledoux ${ }^{2}{ }^{\mathbb{D}}$, Gianina Crișan ${ }^{1}$ and Ramona Păltinean ${ }^{1}$ \\ 1 Department of Pharmaceutical Botany, Faculty of Pharmacy, "Iuliu Hațieganu” University of Medicine and \\ Pharmacy, 400337 Cluj-Napoca, Romania; irina.ielciu@umfcluj.ro (I.I.); gcrisan@umfcluj.ro (G.C.); \\ rpaltinean@umfcluj.ro (R.P.) \\ 2 Laboratory of Pharmacognosy, Center of Interdisciplinary Research on Medicines, University of Liège, \\ 4000 Liège, Belgium; M.Frederich@uliege.be (M.F.); l.angenot@uliege.be (L.A.); \\ allison.ledoux@uliege.be (A.L.) \\ 3 Department of Pharmacognosy, Faculty of Pharmacy, "Iuliu Haţieganu” University of Medicine and \\ Pharmacy, 400010 Cluj-Napoca, Romania \\ 4 PlantExtrakt Ltd., Rădaia, 407059 Cluj-Napoca, Romania; neliolah@yahoo.com \\ 5 Department of Pharmaceutical Industry, Faculty of Pharmacy, “Vasile Goldiş” Western University of Arad, \\ 310045 Arad, Romania \\ * Correspondence: dhanganu@umfcluj.ro
}

Received: 5 April 2019; Accepted: 17 April 2019; Published: 20 April 2019

\begin{abstract}
Bryonia alba L. is the only Bryonia species found in Romanian flora, being known as a remedy for inflammatory pathologies or for its hepatoprotective and adaptogen activities. The present investigation studied the flavonoid composition and antioxidant activities of the aerial parts of this species. Flavonoid profile was evaluated by HPLC coupled with Diode Array Detection (DAD), while antioxidant capacity was assessed by various methods, testing different antioxidant mechanisms: DPPH (2,2-diphenyl-1-picrylhydrazyl), CUPRAC (cupric reducing antioxidant capacity), FRAP (ferric reducing ability of plasma), TEAC (Trolox equivalent antioxidant capacity), EPR (electron paramagnetic resonance method) and SNPAC (silver nanoparticles antioxidant capacity). Cytotoxicity was tested on human cancerous and healthy cell lines. Anti-plasmodial tests were performed on two strains of Plasmodium falciparum. Whole organism toxicity was assessed on zebrafish larvae. The HPLC-DAD analysis proved the presence of lutonarin, saponarin, isoorientin, and isovitexin as the major flavonoids in the composition of tested samples. Significant results were obtained for all antioxidant capacity assays. The cytotoxicity tests proved the absence of cellular and parasitic toxicity and these results were confirmed by the lack of toxicity on the zebrafish larvae model. This study proves a promising potential of the aerial parts of Bryonia alba $\mathrm{L}$. as antioxidant agents.
\end{abstract}

Keywords: flavonoids; HPLC-DAD; antioxidant; toxicity

\section{Introduction}

The Cucurbitales order is a taxonomic unit with worldwide distribution, having significant diversity in species. It comprises almost 2600 species, contains around 110 genera, and it is divided in seven families, mostly found in temperate climates: Anisophylaceae, Begoniaceae, Coriariaceae, Corynocarpaceae, Cucurbitaceae, Datisticaceae, and Tetramelaceae [1,2]. Among these families, the Cucurbitaceae family is the largest, comprising over 100 genera and 800 species [1], mostly found in tropical and subtropical regions, in south-eastern Asia, western Africa, Madagascar, and Mexico [1,3,4]. Cucurbitaceae species can also be found naturalized in Europe, in different areas, especially in the 
southern, central and eastern parts of the continent. Because a significant number of species are used for economic purposes, their cultivation is highly spread, especially in southern Europe [3].

Among the Cucurbitaceae genera found in Europe, Bryonia is one of the largest, comprising 10 species, distributed from the Mediterranean to Central European region [3], Northern Africa and Central Asia [1,5]. Kocyan et al. [5] included this genus in the Cucurbitoideae subfamily, Bryonieae tribe, which also includes, together with the 10 Bryonia species, the Ecballium elaterium (L.) A. Rich. species $[5,6]$. Relationships between the two genera are related to morphological characteristics and to medicinal uses. Differences especially concern the breeding system, as E. elaterium comprises two subspecies with different breeding systems (subspecies dioicum, which is dioecious, and subspecies elaterium, which is monoecious), while in the Bryonia genus seven species are dioecious and three are monoecious $[7,8]$.

In the Romanian flora, Bryonia has been the only genus of the Cucurbitaceae family that created confusion among botanists. The presence of two species is cited: B. alba L. and B. dioica Jacq., but confusions are especially related to the latter. Tutin et al., in Flora Europaea, cite the presence of one species, Bryonia cretica L., with three subspecies, namely cretica, dioica, and acuta [3], including the species B. dioica as a subspecies of B. cretica. Romanian sources cite the presence of Bryonia dioica Jacq. $[9,10]$, whilst the most recent sources regarding Romanian flora cite the presence of Bryonia cretica $\mathrm{L}$. subsp. dioica [11], probably following the classification of Flora Europaea. The presence of B. dioica in the Romanian country remains uncertain, as it is recorded as doubtful by Săvulescu et al. in an older Romanian flora [9]. In a more recent flora of Romania, Ciocârlan et al. describe the presence of the species in Arad, Radna, and Bucharest [10]. Studies performed by Volz and Renner in 2008 and $2009[6,12]$ cite its presence as uncertain, stating that it might have escaped from the Botanical Garden in Bucharest, Romania.

Confusions between these species are due to the large number of similarities between them. However, differences can also be found. The most significant difference between these species, besides morphological characteristics, is found in the breeding system, as $B . a l b a \mathrm{~L}$. is a monoecious species, while $B$. cretica $L$. and B. dioica Jacq. are dioecious species. Distribution of these species is also different: B. alba ranges from Central Europe to Kazakhstan, while B. cretica L. and B. dioica have different area distributions, especially the southern, central, and eastern parts of Europe, where B. dioica appears to be spreading. Distribution of the major chloroplast haplotypes for Bryonia species, from a geographic point of view, suggest that $B$. alba L. is highly likely to represent the only Bryonia species in Romania and the most widespread Bryonia species in the world [12].

In this context, and taking into consideration that $B$. alba is the only species belonging to the Bryonia genus that has been reported in Romania, it appears necessary to study its chemical composition and biological activity in detail, especially as it is reported to have therapeutic uses $[7,8]$. Not only is this species reported to have important homeopathic uses, but it is also reported to have traditional uses as antipyretic, anti-inflammatory, antibacterial, laxative-purgative, smooth muscle relaxant, cytotoxic, hepatoprotective, and anti-diabetic properties [8], which prove its promising potential for the treatment of various diseases.

The present study was performed in the context of similar studies on this species, and other related species belonging to Cucurbitaceae family, that have aimed to reveal the antioxidant potential of some species belonging to this family that are lesser known for their biological activity or economical uses [13-15]. At the same time, the aim of this study was to reveal the fact that Bryonia alba lacks toxicity in all its aerial parts, and to prove its promising potential as an antioxidant agent. The novelty of the study lies in its testing the lack of toxicity on different in vitro models, namely human cancerous cell lines, healthy cell lines, and parasitic strains, and on one in vivo model, the zebrafish larvae model. The reason for choosing these models lies in the antioxidant activity that was further tested by several non-cellular assays, which can boost a possible antiplasmodial activity. The present study appears in the context of several antioxidant molecules that have been proven to have significant antioxidant activity, showing other important biological activities besides anti-plasmodial (e.g., ellagic 
acid) [16]. Therefore, the aim of this study was to assess the flavonoid composition of the aerial parts of Bryonia alba L., and to evaluate their antioxidant potential, proving at the same time that these parts lack cellular toxicity both in vitro and in vivo.

\section{Materials and Methods}

\subsection{Plant Material}

Aerial parts of Bryonia alba L. were collected from Cluj-Napoca county in July 2014 (north-western Romania) during the flowering period. The vegetal material was identified at the Department of Pharmaceutical Botany of the "Iuliu Haţieganu" University of Medicine and Pharmacy (Cluj-Napoca, Romania), where voucher specimens nr. 105.3.1.1-12 were deposited in the Herbarium of the Department.

\subsection{Extraction Procedure}

The collected vegetal material was ground in order to obtain a fine powder. Vegetal powder (50 g) was macerated with $500 \mathrm{~mL}$ methanol for $24 \mathrm{~h}$. Subsequently, powder was subjected to percolation and the obtained solution was evaporated under vacuum at $40^{\circ} \mathrm{C}$. The crude extract obtained was subjected to the analysis of compounds by HPLC coupled with Diode Array Detection (HPLC-DAD) analysis and to evaluation of antioxidant capacity after being dissolved in analytical grade ethanol (Merck, Darmstadt, Germany). Samples that were subjected to cytotoxicity assays were obtained by dissolving crude extracts in dimethyl sulfoxide (DMSO, Merck, Darmstadt, Germany) at a concentration of $10 \mathrm{mg} / \mathrm{mL}$, while for whole organism toxicity test on zebrafish, crude extracts were suspended in the water used for the development of zebrafish larvae (concentration $1 \mathrm{mg} / \mathrm{mL}$ ) [15].

\subsection{Chemicals}

Folin-Ciocâlteu reagent, sodium carbonate, gallic acid, aluminium chloride, sodium acetate, and rutin were purchased from Sigma-Aldrich (Darmstadt, Germany). Flavonoid references used for HPLC-DAD analysis (saponarin-purity $\geq 98 \%$, isoorientin-purity $\geq 99 \%$, and isovitexin-purity $\geq 99 \%$ ) were obtained from Extrasynthèse (Lyon, France). Human cancerous cell lines (HeLa, A549) and human healthy cell line (WI-38) were obtained from the Laboratory of Medical Chemistry (GIGA Center, University of Liège, Liège, Belgium). All reagents used for cell culture assays were purchased from Bio-Whittaker-Lonza (Verviers, Belgium). Cell proliferation reagent (WST-1) was purchased from Roche (Bâle, Switzerland). Reagents for antioxidant assays were purchased from Sigma-Aldrich (Darmstadt, Germany).

\subsection{Determination of Total Phenolic Content (TPC)}

The total phenolic content (TPC) was evaluated by a method that uses the Folin-Ciocâlteu reagent, with some changes compared to the classical one. Methanolic extract $(2.0 \mathrm{~mL})$ was diluted 25 times and then mixed with $1.0 \mathrm{~mL}$ Folin-Ciocâlteu reagent and $10.0 \mathrm{~mL}$ of distilled water, and diluted to $25.0 \mathrm{~mL}$ with $290 \mathrm{~g} / \mathrm{L}$ sodium carbonate. After $30 \mathrm{~min}$ incubation in the dark, absorbance of the solution was determined at $760 \mathrm{~nm}$. Results were expressed as $\mathrm{mg}$ gallic acid equivalents (GAE)/100 g dry vegetal product $(\mathrm{dvp})$, using a calibration curve based on gallic acid $\left(R^{2}=0.998\right)$. Spectrophotometric data were acquired using a Jasco V-530 UV-Vis spectrophotometer (Jasco International Co., Ltd., Tokyo, Japan) [17].

\subsection{Determination of Total Flavonoid Content (TFC)}

The total flavonoid content (TFC) was assessed by a spectrophotometric method based on the formation of the aluminum chloride complex. Methanolic extract $(5.0 \mathrm{~mL})$ was mixed with $5.0 \mathrm{~mL}$ sodium acetate $100 \mathrm{~g} / \mathrm{L}, 3.0 \mathrm{~mL}$ aluminum chloride $25 \mathrm{~g} / \mathrm{L}$ and completed to $25.0 \mathrm{~mL}$ in a calibrated 
flask. Absorbance of the resulted solution was measured at $430 \mathrm{~nm}$. Results were expressed as mg rutin equivalents $(\mathrm{RE}) / 100 \mathrm{~g}$ dvp, using a calibration curve based on rutin $\left(R^{2}=0.999\right)[17,18]$.

\subsection{Identification and Quantification of Flavonoids}

HPLC-DAD Analysis of Flavonoids

Flavonoids were analyzed by a method described by Ielciu et al. [15]. Crude extracts dissolved in methanol $(1 \mathrm{mg} / \mathrm{mL})$ were filtered through a $0.45 \mathrm{~mm}$ membrane and injected into a Hewlett Packard Agilent 1100 system (Agilent, Santa Clara, California, USA), equipped with an Agilent 1100 quaternary pump (Agilent, Santa Clara, California, USA), an Agilent 1100 degaser, and an Agilent 1100 Automatic Liquid Sampler (Agilent, Santa Clara, California, USA ). Mobile phases were represented by $0.05 \% V / V$ triflouroacetic acid in water (A) and acetonitrile (B), at a flow rate of $1 \mathrm{~mL} / \mathrm{min}$, with the following gradient composition: 0 to $1 \mathrm{~min} 0 \% \mathrm{~B} ; 1$ to $45 \mathrm{~min} \mathrm{3 \%} \mathrm{B;} 45$ to $55 \mathrm{~min} 40 \% \mathrm{~B} ; 55$ to $56 \mathrm{~min} 60 \% \mathrm{~B} ; 56$ to $66 \mathrm{~min} 60 \% \mathrm{~B} ; 66$ to $67 \mathrm{~min} 0 \% \mathrm{~B}$; and 67 to $82 \mathrm{~min} 0 \%$ B. For separation, a Hypersil ODS C18 column $(250 \mathrm{~mm} \times 4$.6, i.d.; particle size $5 \mu \mathrm{m})$ was used. Temperature of separation was set at $25^{\circ} \mathrm{C}$. Detection of flavonoids was performed at $350 \mathrm{~nm}$ on an Agilent 1200 Diode Array Detector (Agilent, Santa Clara, California, USA). In order to identify the flavonoids, comparison of retention times and UV-VIS spectra of reference compounds was performed.

\subsection{Antioxidant Activity Assays}

\subsubsection{DPPH Assay}

The classical DPPH method is based on the neutralization of the 2,2-diphenyl-1-picrylhydrazyl $(\mathrm{DPPH})$ free radical, which changes the color from violet to yellow in the presence of an antioxidant. The color change is correlated with the antioxidant capacity, and is evaluated by spectrophotometry at $517 \mathrm{~nm}$. A mixture of $5 \mathrm{~mL}$ of DPPH $(25 \mathrm{mM})$ and $5 \mathrm{~mL}$ of sample was incubated for $30 \mathrm{~min}$ at $40^{\circ} \mathrm{C}$. The reference solution consisted in a mixture of $5 \mathrm{~mL}$ of DPPH and $5 \mathrm{~mL}$ methanol, and the blank consisted of methanol. Results were expressed as $\mathrm{IC}_{50}(\mu \mathrm{g} / \mathrm{mL})$, whichrepresents the concentration of extract that is necessary to cause $50 \%$ inhibition of the radical. The following formula was used in order to determine the inhibition percentage: $\mathrm{I} \%=(\mathrm{Ar}-\mathrm{As}) \times 100 / \mathrm{Ar}$, where $\mathrm{Ar}$ is the absorbance of the reference solution and As is the absorbance of the sample. Quercetine and butyl-hydroxytoluene (BHT) were used as positive controls $[19,20]$.

\subsubsection{Trolox Equivalents Antioxidant Capacity (TEAC) Assay}

The assay evaluates the capacity of an antioxidant to reduce the 2,2-azino-bis-(3-ethylbenzothiazoline-6-sulfonic acid) free cationic radical $\left(\mathrm{ABTS} \bullet^{+}\right)$by adding a solution of potassium persulfate. The method assesses by spectrophotometry the color change of the initial solution from blue to yellow or colorless. To $1 \mathrm{~mL}$ of $7.5 \mathrm{mM}$ ABTS solution, $1 \mathrm{~mL}$ of $2.6 \mathrm{mM}$ potassium persulfate solution was added and the mixture was incubated for $12 \mathrm{~h}$ in the dark. Methanol $(60.0 \mathrm{~mL})$ was then added to $1 \mathrm{~mL}$ of this mixture (ABTS reagent). At $1 \mathrm{~mL}$ of sample, the ABTS solution was added and incubated in the dark for $2 \mathrm{~h}$. The color change was assessed by a spectrometric determination of the absorbance at $734 \mathrm{~nm}$. The reference solution consisted of the same mixture using methanol instead of the samples. The blank consisted of methanol. Results are expressed as $\mathrm{IC}_{50}(\mu \mathrm{g} / \mathrm{mL})$, compared to a Trolox standard. The same formula as in the case of DPPH was used to calculate the inhibition percentage [19,21,22].

\subsubsection{CUPRAC (Cupric Reducing Antioxidant Capacity) Assay}

This assay evaluates the change of color determined by the reduction of the copper ion II to the copper ion I, which takes place in the complex 2,9-dimethyl-1,10-phenantroline (neocupreine). The color change from light green to orange is correlated with the concentration of the antioxidant, and the 
absorbance which is correlated was measured at $450 \mathrm{~nm}$. The CUPRAC reagent consisted of a mixture of $1 \mathrm{~mL} 7.5 \mathrm{mM}$ neocupreine solution, $1 \mathrm{~mL} 10 \mathrm{mM}$ copper chloride solution, and $1 \mathrm{~mL}$ ammonium acetate buffer at $\mathrm{pH}=6.8$. At $1 \mathrm{~mL}$ of sample, the CUPRAC reagent was added, and after incubation for 30 minutes at room temperature, absorbance was measured. The blank consisted of a solution that contained water instead of the sample. Results were expressed as $\mathrm{mM}$ Trolox equivalents $/ 100 \mathrm{~mL}$ extract, using a calibration curve plotted with different concentration of Trolox [20,23].

\subsubsection{FRAP (Ferric Reducing Ability of Plasma) Assay}

The ion reduced in this assay is iron, which is reduced from the ferric ion to the ferrous ion in a complex of iron with the radical 2,4,6-tripyridyl-s-triazine (TPTZ). Reduction of this ion is assessed by measuring the absorbance determined by the color change from green to yellow or blue, at $593 \mathrm{~nm}$. The FRAP reagent consists of a mixture of $2.5 \mathrm{ml} 10 \mathrm{mM}$ TPTZ solution in $40 \mathrm{mM}$ hydrochloric acid, to which $2.5 \mathrm{ml} 20 \mathrm{mM}$ ferric chloride solution and $25 \mathrm{ml}$ acetate buffer at $\mathrm{pH}=3.6$ was added. At $1 \mathrm{~mL}$ of sample, $6 \mathrm{~mL}$ of the FRAP reagent was added and absorbance was measured. The blank consisted of a solution that contained water instead of the sample. Results are expressed as mM Trolox equivalents/100 mL extract, using a calibration curve plotted with concentrations of a Trolox standard $[19,20,24]$.

\subsubsection{SNPAC (Silver Nanoparticles Antioxidant Capacity) Assay}

The basis of this assay is represented by the silver nanoparticles (SNP) that are obtained by reducing silver ions from silver nitrate, using as surface stabilizer trisodium citrate. The silver ion is reduced to colloidal silver, using the SNP suspended in solution, by the potential antioxidants. The color change from yellow to brown is assessed by measuring the absorbance at $423 \mathrm{~nm}$, using the calibration curve plotted using the Trolox standard. At $2 \mathrm{~mL}$ of SNP reagent obtained from $10 \mathrm{mM}$ silver nitrate solution and $1 \%$ trisodium citrate solution at $100{ }^{\circ} \mathrm{C}, 1 \mathrm{~mL}$ of the sample was added. The mixture was incubated at room temperature for $30 \mathrm{~min}$. The blank consisted of a solution that contained water instead of samples. Results are expressed as mM Trolox equivalents/100 mL extract [18,23].

\subsubsection{EPR (Electron Paramagnetic Resonance) Assay}

Using the DPPH radical added to the extract, this method records the EPR spectra of the mixture. Measurements were performed on a Bruker Elexsys E500 spectrometer (Bruker, Billerica, MA, USA), in EPR quartz capillaries. The difference between samples and the DPPH radical were expressed as integral intensity (I), which was compared to that of a $4.5 \mathrm{mM}$ DPPH reference, mixed with $10 \mu \mathrm{L}$ of extract and transferred into the EPR quartz capillaries. Measurements were performed in X band $(\sim 9.4 \mathrm{GHz})$, at room temperature, with a frequency modulation of $100 \mathrm{kHz}$. Parameters used for the evaluation of samples were: center field $3360 \mathrm{G}$; sweep width $60 \mathrm{G}$; power $2 \mathrm{~mW}$; receiver gain $1 \times 103$; modulation amplitude $2 \mathrm{G}$; time of conversion $15 \mathrm{~ms}$; time constant $30.72 \mathrm{~ms}$; sweep time 60s. EPR spectra were recorded at different time intervals. Variations of the relative concentration of paramagnetic species were obtained through double integration of experimental spectra using XEPR Bruker software Bruker, Billerica, USA) [18,23,25].

\subsection{Cytotoxicity Assays}

The cell lines used to test the cytotoxicity were the A549 (lung cancer), HeLa (cervical cancer), and WI38 (fetal lung fibroblasts) cell lines. Each of these cell lines was cultured in DMEM medium, supplemented with 10\% heat-inactivated fetal bovine serum (FBS), 1\% L-glutamine (200 mM), and penicillin $(100 \mathrm{IU} / \mathrm{mL})-$ streptomycin $(100 \mu \mathrm{g} / \mathrm{mL})$, as described by Ledoux et al. [26]. A total 8000 cells were seeded per well in microplates. After $24 \mathrm{~h}$, dilutions of the samples were added to each well and incubated together for $48 \mathrm{~h}$. Concentrations of samples ranged between 2 and $100 \mu \mathrm{g} / \mathrm{mL}$. Cell viability was assessed after $48 \mathrm{~h}$ by adding WST-1 tetrazolium salt and measuring absorbances at $450 \mathrm{~nm}$ on a Multiwell Scanner (Stat Fax 2100, Awareness Technology, Perchtoldsdorf, Austria). Samples were 
tested in triplicate, and tests were performed twice. For each sample, $\mathrm{IC}_{50}$ was calculated by linear regression, by comparison with the negative control (non-treated cells). Camptothecin was used as the positive reference [26,27].

\subsection{Anti-Plasmodial Assays}

Assays were performed on two Plasmodium falciparum strains: 3D7 (chloroquine sensitive) and W2 (chloroquine resistant). Eight two-fold dilutions of samples in culture medium were incubated with a parasitic suspension for $48 \mathrm{~h}$ in 96 well microplates. Tested concentrations of samples ranged between 0.8 and $100 \mu \mathrm{g} / \mathrm{mL}$. Inhibition of parasite growth was evaluated by spectrophotometry, by assessing the activity of the plasmodial lactate dehydrogenase (pLDH) at $630 \mathrm{~nm}$. Absorbances were determined using a Multiwell scanner (Stat Fax 2100, Awareness Technology Inc). Positive reference for the inhibition of parasite growth was represented by artemisinin (Sigma-Aldrich), while positive and negative controls were represented by infected and uninfected erythrocytes. Inhibition of parasite growth was evaluated by comparison with non-treated erythrocytes infected with parasites, which represent $100 \%$ growth. $\mathrm{IC}_{50}$ values were calculated by linear regression from the concentrations range of samples. Each sample was tested two times in each test, and tests were performed in triplicate for each strain $[26,28]$.

\subsection{Zebrafish Toxicity Assays}

Zebrafish (Danio rerio) were maintained in special conditions, according to the criteria of the Ethical Committee for the Use of Laboratory Animals (University of Liège, Liège, Belgium). Fertilized eggs were incubated at $28{ }^{\circ} \mathrm{C}$ and maintained on a $14 \mathrm{~h}$ day/10 h night period throughout the experiment. Larvae were collected and their chorions were removed. The larvae medium containing the crude extract (concentrations between 0.1 and $100 \mu \mathrm{g} / \mathrm{mL}$ ) was replaced once per day. Embryos were observed each day until $72 \mathrm{hpf}$ (hours post fertilization). Twenty-five larvae were treated once daily with $5 \mathrm{~mL}$ of each sample concentration, and another 25 were used as control $[15,26]$.

\subsection{Statistical Analysis}

Data are presented as mean values \pm standard deviation (SD). For each assay, samples were analyzed in triplicate. Averages and SD were calculated using the Excel software package [13,14].

\section{Results and Discussion}

\subsection{Identification and Quantification of Flavonoids by HPLC-DAD}

In the crude extract obtained from the aerial parts of Bryonia alba L., four flavonoids were identified: lutonarin, saponarin, isoorientin, and isovitexin, as seen in Table 1. Identification of these compounds was performed by comparison with commercially available references, which were analyzed in the same chromatographic conditions. For saponarin, isoorientin, and isovitexin, identification was achieved by comparing UV spectra of the existing references, while for lutonarin, identification was achieved by MS and NMR RMN. Previous reports exist for the presence of lutonarin, saponarin, and isovitexin $[29,30]$ in the aerial parts of this species, while this is the first report for isoorientin, its presence being confirmed only in studies performed on the leaves of the species [15].

Table 1. The four flavonoids which are identified in the aerial parts of Bryonia alba.

\begin{tabular}{ccc}
\hline Compound & Peak Number & Retention Time \\
\hline Lutonarin & 1 & $22.55 \pm 0.27 \mathrm{~min}$ \\
Saponarin & 2 & $24.78 \pm 0.16 \mathrm{~min}$ \\
Isoorientin & 3 & $25.98 \pm 1.01 \mathrm{~min}$ \\
Isovitexin & 4 & $28.87 \mathrm{~min}$ \\
\hline
\end{tabular}




\subsection{Determination of Total Phenolic Content (TPC) and Total Flavonoid Content (TFC)}

Results obtained for the quantification of the TPC and TFC can be found in Table 2, and can be correlated with the results obtained in the biological assays, especially in the assays used to evaluate the antioxidant capacity. This is the first report that quantifies the TPC and TFC for the aerial parts of this species. Other studies performed by our team report similar amounts of both types of compounds for a species belonging to Cucurbitaceae family, Echinocystis lobata Torr. et A. Gray, using similar methods and similar type of samples. If comparing the results obtained for the quantification of these compounds in the aerial parts of E. lobata to the ones obtained for the quantification of these compounds in the aerial parts of B. alba, similar amounts appear to be found in all tested samples. For E. lobata, it appears that the TPC and TFC increase as the species reaches its maximal development period. For B. alba, amount of these compounds was close to the ones obtained at the maximal development period of E. lobata, which is in strong correlation with the collecting time, July, when this species reaches its highest peak in the accumulation of these compounds [13].

Table 2. Quantification of the total phenolic content (TPC) and total flavonoid content (TFC) in the aerial parts of Bryonia alba L. (mg GAE or RE/100 g dvp).

\begin{tabular}{ccc}
\hline Sample & $\begin{array}{c}\text { TPC } \\
(\mathbf{m g ~ G A E} / \mathbf{1 0 0} \mathbf{~} \text { dvp })\end{array}$ & $\begin{array}{c}\text { TFC } \\
\text { (mg RE/100 } \mathbf{g ~ d v p})\end{array}$ \\
\hline Bryonia alba aerial parts & $3125 \pm 0.31$ & $2472 \pm 0.94$ \\
\hline
\end{tabular}

\subsection{Antioxidant Activity Assays}

Six in vitro assays were used to evaluate the antioxidant capacity of the aerial parts of Bryonia alba. Each of the assays performed provided different results, but connections between these results and the flavonoid analyses could be established. Results obtained for the assessment of the antioxidant capacity can be found in Table 3. It can be observed that the aerial parts of the species presented significant antioxidant capacity. This is the first report that evaluates the antioxidant capacity of the aerial parts of this species, antioxidant activity having been reported by other mechanisms and type of assays, using cellular approaches, for the leaves of the species [15].

Table 3. Assessment of the antioxidant capacity of the aerial parts of Bryonia alba $\mathrm{L}$. $\left(\mathrm{IC}_{50} \mu \mathrm{g} / \mathrm{mL}\right.$ or $\mu \mathrm{M}$ $\mathrm{TE} / 100 \mathrm{~mL})$.

\begin{tabular}{|c|c|}
\hline Sample & Bryonia alba Aerial Parts \\
\hline DPPH $\left(\mathrm{IC}_{50} * \mu \mathrm{g} / \mathrm{mL}\right)$ & $99.8 \pm 0.92$ \\
\hline CUPRAC ( $\mu \mathrm{M}$ TE/100 mL) & $238 \pm 2.24$ \\
\hline FRAP $(\mu \mathrm{M}$ TE/100 mL) & $217 \pm 2.45$ \\
\hline TEAC $\left(\mathrm{IC}_{50}{ }^{* *} \mu \mathrm{g} / \mathrm{mL}\right)$ & $19.9 \pm 0.89$ \\
\hline SNPAC $(\mu \mathrm{M}$ TE/100 mL) & $427 \pm 2.46$ \\
\hline EPR (Integral intensity ***) & $401.96 \pm 2.72$ \\
\hline
\end{tabular}

Positive controls: * quercetine: $\mathrm{IC}_{50}=5.4 \pm 0.32 \mu \mathrm{g} / \mathrm{mL}$ and BHT: $\mathrm{IC}_{50}=15.6 \pm 0.44 \mu \mathrm{g} / \mathrm{mL}$; ${ }^{* *}$ Trolox $\mathrm{IC}_{50}=17.4 \pm 0.26 \mu \mathrm{g} / \mathrm{mL} ;{ }^{* * *} \mathrm{DPPH}$ Integral Intensity $=668.62 \pm 0.18$. Note: Values are the mean $\pm \mathrm{SD}(n=3)$.

It can be noticed that results obtained for the quantification of TPC and TFC are strongly correlated to the results obtained in the antioxidant activity assays. Similar research performed by our team on the flowers, leaves, and aerial parts of Echinocystis lobata Torr. et A. Gray, also belonging to the Cucurbitaceae family, reveal that the antioxidant potential of the aerial parts of Bryonia alba L. is important and superior to that of E. lobata $[13,14]$. Results obtained for the same assays in the evaluation of the antioxidant capacity of the aerial parts of E. lobata show that, for the all the assays that were used, the potential of the B. alba aerial parts is at least similar to that obtained for E. lobata. The study 
performed for E. lobata compared the antioxidant potential of this species for samples collected at the beginning and towards the maximal development period of this species. The samples that were tested in the present study were collected in the maximal accumulation period of active compounds for $B$. alba, and it is clear by comparison that their antioxidant potential is similar. For E. lobata, results show values of $\mathrm{IC}_{50}$ of $82.4 \pm 0.85$ and $16 \pm 0.26$ for the DPPH and TEAC assays, while for CUPRAC, FRAP, SNPAC, and EPR results were $219 \pm 0.96 \mu \mathrm{M}$ TE/100 mL, $290 \pm 2.75 \mu \mathrm{M}$ TE/ $100 \mathrm{~mL}, 679 \pm 3.69 \mu \mathrm{M}$ $\mathrm{TE} / 100 \mathrm{~mL}$, and $86.01 \pm 0.77$ integral intensity for the same types of sample. Together with the results obtained in the cytotoxicity assays, it is therefore shown that the aerial parts of this species present significant antioxidant capacity. Another study performed by our research team [15] highlights the antioxidant potential of the leaves of $B$. alba, but the present study is the first testing of the antioxidant capacity of the aerial parts of this species, and proving their promising potential as antioxidant agents.

\subsection{Cytotoxicity Assays and Anti-Plasmodial Assays}

Bryonia alba is considered to be a toxic species, especially its roots, which have been cited to contain a toxic class of compounds, cucurbitacins [8]. Studies performed by our team [31] revealed that the aerial parts of the species do not contain these compounds. Moreover, the present study reveals the presence of significant levels of flavonoids.

No cellular toxicity was observed for the tested samples at a concentration of $100 \mu \mathrm{g} / \mathrm{mL}$ or below, either on human cancerous cell lines and on human healthy cell lines. At the same time, anti-plasmodial tests showed no cellular toxicity on the parasitic strains used (Table 4). It could be therefore be established that the tested samples lack in vitro cellular toxicity. In this context, connections with the content of flavonoids could be established, and the potential of the aerial parts as antioxidant agents.

Table 4. Assessment of the cytotoxicity and of the anti-plasmodial activity of the aerial parts of Bryonia alba L. $\left(\mathrm{IC}_{50} \mu \mathrm{g} / \mathrm{mL}\right)$.

\begin{tabular}{ccc}
\hline Assay & Bryonia alba Aerial Parts & Artemisinin/Camptothecin \\
\hline Anti-plasmodial 3D7 $(\mu \mathrm{g} / \mathrm{mL})$ & $>50$ & $0.009 \pm 0.006$ \\
Anti-plasmodial W2 $(\mu \mathrm{g} / \mathrm{mL})$ & $>50$ & $0.017 \pm 0.003$ \\
Cytotoxic A549 $(\mu \mathrm{g} / \mathrm{mL})$ & $>50$ & $0.167 \pm 0.04$ \\
Cytotoxic HeLa $(\mu \mathrm{g} / \mathrm{mL})$ & $>50$ & $0.207 \pm 0.27$ \\
Cytotoxic WI38 $(\mu \mathrm{g} / \mathrm{mL})$ & $>50$ & $0.076 \pm 0.19$ \\
\hline
\end{tabular}

Note: Values are the mean $\pm \operatorname{SD}(n=3)$.

\subsection{Zebrafish Toxicity Assays}

The zebrafish embryo acute toxicity test was used to assess the in vivo toxicity of the crude extract at different concentrations. It is a model used more and more by researchers worldwide as an alternative to animal testing [32], as zebrafish larvae represent early life stages of animals that are not protected until reaching $120 \mathrm{~h}$ after fertilization, when they are considered to be organisms with independent feeding [33]. The reasons for choosing this model for testing special toxicity of samples is related to the fast development of the embryos and also to their transparency, which allows observation of the changes that occur in different biological systems. Before the study, embryos were dechorionated, as chorions are the physical barrier that separate the embryo from the exterior. Thus, the contact of embryos with samples is facilitated. Various parameters were monitored at $24 \mathrm{hpf}, 48 \mathrm{hpf}$, and $72 \mathrm{hpf}$, by comparing the exposed embryos to the control. Cardiovascular parameters such as heart rate and blood circulation, together with dermatological parameters and motility, were evaluated. At the same time, morphological changes in the development of the embryos were monitored. No significant change in these parameters were noticed during the experiment for tested samples (Table 5); all these parameters were found similar to those of the embryos not treated. These observations suggest the lack of toxicity in all observed systems, and therefore a lack of special toxicity. 
Table 5. Observation (40×) of zebrafish exposed to a concentration range of $0.1-100 \mu \mathrm{g} / \mathrm{mL}$ of the aerial parts of Bryonia alba compared to the control at $24 \mathrm{hpf}, 48 \mathrm{hpf}$, and $72 \mathrm{hpf}$.

\begin{tabular}{|c|c|c|c|}
\hline Sample & $\begin{array}{l}\text { Zebrafish Assay Results } \\
\qquad 24 \mathrm{hpf}\end{array}$ & $\begin{array}{l}\text { Zebrafish Assay Results } \\
48 \mathrm{hpf}\end{array}$ & Zebrafish Assay $72 \mathrm{hpf}$ \\
\hline $\begin{array}{l}\text { Bryonia alba aerial parts } \\
\qquad 100 \mu \mathrm{g} / \mathrm{mL}\end{array}$ & s. & & \\
\hline $\begin{array}{l}\text { Bryonia alba aerial parts } \\
\qquad 10 \mu \mathrm{g} / \mathrm{mL}\end{array}$ & & & \\
\hline $\begin{array}{l}\text { Bryonia alba aerial parts } \\
\qquad 1 \mu \mathrm{g} / \mathrm{mL}\end{array}$ & & $862=$ & 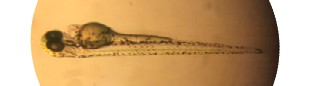 \\
\hline \multicolumn{4}{|l|}{$\begin{array}{l}\text { Bryonia alba aerial parts } \\
\qquad 0.1 \mu \mathrm{g} / \mathrm{mL}\end{array}$} \\
\hline \multicolumn{4}{|l|}{ Non-treated zebrafish } \\
\hline & $\begin{array}{c}\text { Negative } \\
\text { control }\end{array}$ & $\begin{array}{c}\text { Negative } \\
\text { control }\end{array}$ & $\begin{array}{c}\text { Negative } \\
\text { control }\end{array}$ \\
\hline
\end{tabular}

\section{Conclusions}

Analysis of flavonoids in the aerial parts of Bryonia alba L. showed the presence of four main flavonoids: lutonarin, saponarin, isoorientin, and isovitexin. The biological potential of these aerial parts was assessed by several in vitro and in vivo tests, which proved the lack of toxicity both to human cancerous and healthy cell lines and on parasitic strains. In this context, by using non-cellular assays, the antioxidant potential of these parts of the species could be established. The present study represents a promising premise for further tests that can support the use of these parts as medicinal products for different therapeutic purposes.

Author Contributions: Important contributions to design and to preparing the manuscript: I.I., R.P., M.F., D.H., N.-K.O., L.A., A.L., G.C. Phytochemical screening, cytotoxicity tests, and antiplasmodial assays were performed by: I.I., R.P., A.L. Contributed to antioxidant and antimicrobial experiments: I.I., D.H, N.-K.O. Analysis of the experimental data: I.I., R.P., M.F., D.H., N.-K.O., L.A., A.L., G.C. Revising it critically for important intellectual content: I.I., R.P., M.F., D.H., N.-K.O., L.A., A.L., G.C. All authors helped in preparing the paper and approved the final version. 
Funding: This research received no external funding.

Acknowledgments: Authors acknowledge Hélène Pendeville from the Zebrafish Platform Facility and Transgenics (GIGA center, University of Liège, Liège, Belgium) for technical assistance concerning the zebrafish model.

Conflicts of Interest: The authors declare no conflict of interest.

\section{References}

1. Schaefer, H.; Renner, S.S. Phylogenetic relationships in the order Cucurbitales and a new classification of the gourd family (Cucurbitaceae). Taxon 2011, 60, 122-138. [CrossRef]

2. Zhang, L.-B.; Simmons, M.P.; Kocyan, A.; Renner, S.S. Phylogeny of the Cucurbitales based on DNA sequences of nine loci from three genomes: Implications for morphological and sexual system evolution. Mol. Phylogenet. Evol. 2006, 39, 305-322. [CrossRef]

3. Tutin, T.G.; Burges, N.A.; Chater, A.O.; Edmonson, J.R.; Heywood, V.H.; Moore, D.M.; Valentine, D.H.; Walters, S.M.; Webb, D.A. Flora Europaea (Rosaceae to Umbelliferae); Cambridge University Press: London, UK, 2010; Volume 2, pp. 297-299.

4. Stevens, P.F. Angiosperm Phylogeny Group. Angiosperm Phylogeny Website. 2012. Available online: http://www.mobot.org/MOBOT/research/APweb/ (accessed on 5 April 2019).

5. Kocyan, A.; Zhang, L.-B.; Schaefer, H.; Renner, S.S. A multi-locus chloroplast phylogeny for the Cucurbitaceae and its implications for character evolution and classification. Mol. Phylogenet. Evol. 2007, 44, 553-577. [CrossRef]

6. Volz, S.M.; Renner, S.S. Hybridization, polyploidy, and evolutionary transitions between monoecy and dioecy in Bryonia (Cucurbitaceae). Am. J. Bot. 2008, 95, 1297-1306. [CrossRef]

7. Rus, L.M.; Ielciu, I.; Păltinean, R.; Vlase, L.; Ştefănescu, C.; Crişan, G. Morphological and Histo-Anatomical Study of Bryonia alba L. (Cucurbitaceae ). Not. Bot. Horti Agrobot. 2015, 43, 47-52. [CrossRef]

8. Ielciu, I.; Frédérich, M.; Tits, M.; Angenot, L.; Păltinean, R.; Cieckiewicz, E.; Crişan, G.; Vlase, L. Bryonia alba L. and Ecballium elaterium (L.) A. Rich.-Two related species of the Cucurbitaceae family with important pharmaceutical potential. Farmacia 2016, 64, 323-332.

9. Săvulescu, T. Flora Republicii Populare Române; Editura Academiei Republicii Populare Române: Bucureşti, România, 1955; pp. 27-52.

10. Ciocârlan, V. Flora ilustrată a României-Pteridophyta et Spermatophyta; Editura Ceres: Bucureşti, România, 2000; pp. 579-582.

11. Sârbu, I.; Ştefan, N.; Oprea, A. Plante Vasculare din România; Editura Victor B Victor: Bucureşti, România, 2013; pp. 528-530.

12. Volz, S.M.; Renner, S.S. Phylogeography of the ancient Eurasian medicinal plant genus Bryonia (Cucurbitaceae) inferred from nuclear and chloroplast sequences. Taxon 2009, 58, 550-560. [CrossRef]

13. Ielciu, I.; Vlase, L.; Frédérich, M.; Hanganu, D.; Păltinean, R.; Cieckiewicz, E.; Olah, N.K.; Gheldiu, A.M.; Crişan, G. Polyphenolic profile and biological activities of the leaves and aerial parts of Echinocystis lobata (Michx.) Torr. et A. Gray (Cucurbitaceae). Farmacia 2017, 65, 179-183.

14. Ielciu, I.; Hanganu, D.; Păltinean, R.; Vlase, L.; Frédérich, M.; Gheldiu, A.M.; Benedec, D.; Crişan, G. Antioxidant capacity and polyphenolic content of the Echinocystis lobata (Michx.) Torr. et A.Gray flowers. Pak. J. Pharm. Sci. 2018, 31 (Suppl. 2), 677-683.

15. Ielciu, I.; Mouithys-Mickalad, A.; Franck, T.; Angenot, L.; Ledoux, A.; Păltinean, R.; Cieckiewicz, E.; Etienne, D.; Tits, M.; Crişan, G.; et al. Flavonoid composition, cellular antioxidant activity and (myelo)peroxidase inhibition of a Bryonia alba L. (Cucurbitaceae) leaves extract. J. Pharm. Pharmacol. 2019, 71, 230-239. [CrossRef]

16. Ríos, J.-L.; Giner, R.; Marín, M.; Recio, M. A Pharmacological Update of Ellagic Acid. Planta Med. 2018, 84, 1068-1093. [CrossRef]

17. Benedec, D.; Hanganu, D.; Oniga, I.; Filip, L.; Bischin, C.; Silaghi-Dumitrescu, R.; Tiperciuc, B.; Vlase, L.; McPhee, D.J. Achillea schurii Flowers: Chemical, Antioxidant, and Antimicrobial Investigations. Molecules 2016, 21, 1050. [CrossRef]

18. Benedec, D.; Filip, L.; Vlase, L.; Bele, C.; Sevastre, B.; Raita, O.; Olah, N.-K.; Hanganu, D. In vitro study of antioxidant activity and phenolic content of Chrysanthemum balsamita varieties. J. Pharm. Sci. 2016, 29, 1359-1364. 
19. Thaipong, K.; Boonprakob, U.; Crosby, K.; Cisneros-Zevallos, L.; Hawkins Byrne, D. Comparison of ABTS, DPPH, FRAP, and ORAC assays for estimating antioxidant activity from guava fruit extracts. J. Food Compos. Anal. 2006, 19, 669-675. [CrossRef]

20. Olah, N.K.; Osser, G.; Câmpean, R.F.; Furtună, F.R.; Benedec, D.; Filip, L.; Raita, O.; Hanganu, D. The study of polyphenolic compounds profile of some Rosmarinus officinalis L. extracts. Pak. J. Pharm. Sci. 2016, 29, 2355-2361.

21. Arnao, M.; Cano, A.; Acosta, M. The hidrophilic and lipophilic contribution to total antioxidant activity. Food Chem. 2001, 73, 239-244. [CrossRef]

22. Hanganu, D.; Filip, L.; Olah, N.K.; Mocan, A.; Vlase, L.; Raita, O.; Oniga, I.; Benedec, D. Evaluation of polyphenolic profile and antioxidant activity for Cytisus nigricans and Cytisus albus. Farmacia 2016, 64, 863-867.

23. Özyürek, M.; Güngör, N.; Baki, S.; Güçlü, K.; Apak, R. Development of a Silver Nanoparticle-Based Method for the Antioxidant Capacity Measurement of Polyphenols. Anal. Chem. 2012, 84, 8052-8059. [CrossRef]

24. Benzie, I.F.; Strain, J. The Ferric Reducing Ability of Plasma (FRAP) as a Measure of "Antioxidant Power": The FRAP Assay. Anal. Biochem. 1996, 239, 70-76. [CrossRef]

25. Hanganu, D.; Olah, N.K.; Mocan, A.; Vlase, L.; Benedec, D.; Raita, O.; Toma, C.C. Comparative Polyphenolic Content and Antioxidant Activities of Two Romanian Lysimachia Species. Rev. Chim. 2016, 67, 227-231.

26. LeDoux, A.; St-Gelais, A.; Cieckiewicz, E.; Jansen, O.; Bordignon, A.; Illien, B.; Di Giovanni, N.; Marvilliers, A.; Hoareau, F.; Pendeville, H.; et al. Antimalarial Activities of Alkyl Cyclohexenone Derivatives Isolated from the Leaves of Poupartia borbonica. J. Prod. 2017, 80, 1750-1757. [CrossRef]

27. Jansen, O.; Tchinda, A.T.; Loua, J.; Esters, V.; Cieckiewicz, E.; LeDoux, A.; Toukam, P.D.; Angenot, L.; Tits, M.; Balde, A.M.; et al. Antiplasmodial activity of Mezoneuron benthamianum leaves and identification of its active constituents. J. Ethnopharmacol. 2017, 203, 20-26. [CrossRef]

28. Jansen, O.; Tits, M.; Angenot, L.; Nicolas, J.-P.; De Mol, P.; Nikiema, J.-B.; Frédérich, M. Anti-plasmodial activity of Dicoma tomentosa (Asteraceae) and identification of urospermal A-15-O-acetate as the main active compound. Malar. J. 2012, 11, 289. [CrossRef]

29. Krauze-Baranowska, M.; Cisowski, W. Flavone C-glycosides from Bryonia alba and B. dioica. Phytochemistry 1995, 39, 727-729. [CrossRef]

30. Krauze-Baranowska, M.; Cisowski, W. C-glucosides of apigenin from Bryonia alba L. Pol. J Chem. 1992, 66, 951-957.

31. Ielciu, I.I. Comparative Pharmacobotanical Study of Some Species Belonging to Cucurbitaceae Family. Ph.D. Thesis, "Iuliu Haţieganu" University of Medicine and Pharmacy, Cluj-Napoca, Romania, University of Liège, Liège, Belgium, 2017.

32. Ablain, J.; Zon, L.I. Of fish and men: using zebrafish to fight human diseases. Trends Cell Boil. 2013, 23, 584-586. [CrossRef]

33. Strähle, U.; Scholz, S.; Geisler, R.; Greiner, P.; Hollert, H.; Rastegar, S.; Schumacher, A.; Selderslaghs, I.; Weiss, C.; Witters, H.; et al. Zebrafish embryos as an alternative to animal experiments-A commentary on the definition of the onset of protected life stages in animal welfare regulations. Reprod. Toxicol. 2012, 33, 128-132. [CrossRef]

(C) 2019 by the authors. Licensee MDPI, Basel, Switzerland. This article is an open access article distributed under the terms and conditions of the Creative Commons Attribution (CC BY) license (http://creativecommons.org/licenses/by/4.0/). 